\title{
Information, Education and Language Policy in the Linguistic Landscape of an International Airport in New Zealand
}

\author{
Una Cunningham and Jeanette King
}

The study of linguistic landscapes initially centered on public signage in multilingual environments (Landry \& Bourhis, 1997; Spolsky \& Cooper, 1991). The many studies in this field have examined both signage produced by public authorities ("informative signs," Spolsky, 2009) and privately produced advertising signs. Cenoz and Gorter (2006) connected the linguistic landscape of public spaces to the official language policy of the setting. Alongside these studies there have been many studies on the purposes and information in linguistic landscapes associated with semi-public environments, including the classroom environment. In a recent article, Gorter (2018) offers an overview of schoolscape research and points out that signage can have a pedagogical application and also be relevant for language learning. Aiestaran, Cenoz, and Gorter (2010) found that signs in schools are related to the teaching of subject content and language, but also intercultural awareness, establishing behavioral rules, as well as practical or commercial information.

This chapter expands the study of multilingual signs in (semi-)public places by examining signs in an airport. Since the 1970s as airports worldwide have increasingly become private companies, there has been a move toward commercial branding of the airport as a destination (Castro \& Lohmann, 2014). Airports are on the one hand semi-public spaces but as they are increasingly administered by private companies the larger airports have a strong branding and commercial focus. The most recent example of this is the opening in April 2019 of Changi Airport's Jewel shopping mall, which is a landside attraction (Jameson, 2019).

Spolsky (2009: 34) outlines eight major types of sign distinguished by Spolsky and Cooper (1991):

1. Street signs

2. Advertising signs

3. Warning notices and prohibitions

4. Building names

5. Informative signs (directions, hours of opening) 
6. Commemorative plaques

7. Objects (postbox, police call box)

8. Grafitti

In this chapter we describe signs in an airport setting, which, according to the taxonomy above, are informative, but also have an element of educational or sociocultural purpose. By educational, we mean that there is an attempt to facilitate learning. We therefore extend the notion of an "educational" purpose of multilingual signs from the classroom into this public/private environment.

\section{The Setting}

New Zealand is a nation of 4.9 million people located in the South Pacific. Māori, the indigenous inhabitants, comprise 15 percent of the population. In addition to British migrants who settled from the mid-nineteenth century onward, there has been increasing migration in recent years from Asian countries such that New Zealand, or more particularly, the largest city Auckland, is defined as "superdiverse" (Royal Society of New Zealand, 2013) due to the large number of languages and people who were born overseas. Geographically the country consists of two main islands, prosaically named the North and South Islands. While historically, meat and dairy exports have been the main export earners, in 2016 tourism became the largest export industry in terms of foreign exchange earning (Bradley, 2017).

Because New Zealand is an island nation that shares no land borders with other countries, 99 percent of visitors arrive by air (Tsui \& Henderson, 2018). The two largest airports by passenger volume are Auckland International Airport (at the northern end of the North Island) and Christchurch International Airport (located in the middle of the South Island) with Auckland handling 71.4 percent of international arrivals in 2016 and Christchurch handling 14.3 percent (Tsui \& Henderson, 2018: 256). The top nationality for international arrivals into New Zealand is Australia with 1.5 million visitor arrivals, followed by China (just under 500,000) (Stats NZ, 2018). These two countries account for half of international visitor arrivals. Among the top eight nationalities 74 percent are from English-speaking countries (Australia, the United States, the UK and Canada). The other four nationalities imply four different languages: Chinese (Mandarin), German, Japanese, and Korean (Tsui \& Henderson, 2018: 256). At Christchurch Airport we found signs in Chinese, Japanese, and Korean. Signs in German were absent, reflecting possibly the expectation that German tourists know at least some English. Our interview with the airport services manager confirms this: "So it's that idea that culturally again trying to avoid putting a myriad of languages on some signage. Just say 'OK we'll go with the English, the Mandarin, Japanese and Korean', we hoped we'd covered the vast majority of our demographic."

Internationally, smaller-sized airports (those with 5 to 14.99 million passengers

per year), such as both the Christchurch and Auckland Airports, typically market themselves by linking themselves with tourism-related content (Castro \& Lohmann, 2014: 9). Since 2008, Auckland Airport has incorporated a strong Māori focus with 
a carved wooden gateway through which all international arrivals enter (Auckland Airport, 2008: 2). Auckland Airport describes itself as the "gateway to New Zealand" and has recently upgraded its international departures area to incorporate Māori design elements throughout the facility (Paranihi, 2019). In contrast, Christchurch is a main entry point for tourists who are visiting attractions in the southern part of the South Island (notably Queenstown and Milford Sound). Consequently Christchurch Airport sees itself as the "gateway to the South Island" and brands itself as such (Christchurch Airport, 2016: 4). Thus the visual imagery in the airport has a different focus to that evident in Auckland. Internal walls in Christchurch Airport display large photographs, which highlight attractions based on natural features, such as glacier hiking, cruises on the fjords of Fiordland, or bungee jumping from bridges over River Gorges. While these attractions may sometimes be operated by Māori tribes or organizations, the imagery does not particularly reflect Māori culture. Both Auckland and Christchurch Airports play an important role in the tourism sector by not only providing connections to the main tourist destinations and attractions but also distributing information to tourism providers about how to optimize their operations for the international market (see, e.g.,, Christchurch Airport, 2016).

As with most airports there are several areas through which international arrivals

transition on arrival at Christchurch Airport. These areas are termed "airside" as they are controlled areas, which are only accessible to passengers and authorized staff. These areas are listed below in the order in which they are encountered by an international arrival:

1. Airbridge and connecting corridors

2. Duty free

3. Immigration

4. Baggage collection

5. Customs

6. Exit to meeting area, "landside"

For a visual example of this layout, see, for example, Auckland Airport, (2008: 3 ). Those who regularly travel internationally by air will know from experience that movement through these sectors is sequential and designed to maximize throughput and minimize confusion and frustration (Blow, 2013).

\section{Education in the Airport}

Airports can be characterized as spaces where diverse groups of people come into the same space. Many of them are first-time visitors in the space; others are locals who regularly depart from and arrive at the airport. Many will be fully proficient speakers and readers of the majority language; others may have little or no knowledge of that language. Some will need directions to the standard functions of airports (baggage claim, passport/immigration, transit, check-in, etc.); others are at the airport for other reasons, e.g., to meet a returning family member. The information needs of these 
groups are different, and they have different levels of knowledge and experience of the environment within and outside the airport and the expectations of the people they will come into contact there. Supplying these groups with the information they require in a way that is accessible is a fundamental function of airports.

This chapter is structured according to the discursive frames (Coupland \& Garret, 2010) or objects of education that we have identified. Each of these uses a particular set of linguistic choices, which Coupland and Garret (2010) associate with the cultural and symbolic values that are intentionally or unintentionally activated by language choice in a particular context. The activated symbolic values are, of course, unlikely to be the same for the senders, the intended readers, and other incidental readers. In this way, biosecurity information is focused on Asian languages (Chinese, Japanese, and Korean) alongside English; Chinese and Korean are prominent in behavioral information; tourist information is generally in English, and airport branding information uses Chinese and Māori to drive home specific points. While the Ministry for Primary Industries (2018: 10, cited in Sherring, 2019) identified a relative lack of signage in other languages as an issue, in 2016 this study did find signs giving directions in Chinese, Korean, and Japanese at Christchurch Airport.

A particular educational need in the case of entry to New Zealand is the matter of

biosecurity in that many elsewhere innocuous items are strictly regulated. Sherring (2019) describes the efforts put into changing the behavior of international travelers to comply with biosecurity regulations. Airport signage is an important part of this effort. New Zealand's biosecurity program adopts the VADE model (Voluntary, Assisted, Directed, and Enforced) of encouraging compliance, starting with information intended to encourage travelers to follow the rules voluntarily, moving through nudging to more explicit directions and finally to enforcement. One of the reasons passengers in 2017 gave as a barrier to complying was lack of information in their native language (Sherring, 2019). Chinese visitors were found to be most influenced by disposal bins and signage at airports. There is an assumption that New Zealand residents and citizens, including those who are themselves migrants from China, will be more aware of and willing to comply with biosecurity restrictions, so information is aimed at visitors.

Another potential need for the education of travelers is in cases where they are assumed to have different, and in the local context, unacceptable, behavior. Matters such as the appropriate use of toilet facilities and prohibition against smoking and other behavior are often held to be a problem for visitors from some other countries.

Helping newly arrived travelers to learn about New Zealand in general and the local area in particular is a further aspect of education in the airport. Once visitors have actually arrived at their destination airport, local and national tourism interests will want them to experience as much as possible with a view to encouraging return visits. In addition, visitors who come for business purposes can be encouraged to visit tourist destinations while in the vicinity. New Zealand is a long way from anywhere else, and many visitors are aware of its reputation of having an unspoiled nature and the opportunity for a wide variety of outdoor activities. They may be less familiar with other destinations and activities in New Zealand, and this kind of tourist information may increase visitors' spending in the region. 
The final kind of education provided by airports that we will consider here has to do with the airport's branding - the image they want to portray. Part of this has to do with corporate responsibility. Christchurch Airport is a company jointly owned by Christchurch City Council (75 percent) and the NZ government (25 percent). Any kind of participation in official drives of various kinds, such as the airport's engagement in Chinese language week, can cast the airport in a favorable light, and these activities will be more or less prominently presented depending on the level of engagement from the airport. Similarly, government policy on various matters may be part of the airport branding, with associated educational activities and materials reflecting the airport's interpretation of the issue at hand. In this paper we will consider aspects of New Zealand's policy of self-identification as a bicultural nation (Hayward, 2012). We note that in the wider New Zealand context, the use of Māori words and expressions without italicization or glosses in text that is otherwise written in English is increasingly recognized as being an unmarked, integral part of New Zealand English (Macalister, 2006). The official government website notes that "whether you're a visitor to NZ or you live here, it's important to be aware of Māori customs and how to interact in Māori culture" (New Zealand Government, 2019).

\section{Airport Signage}

Airport signage has an important role in perceived service quality. Signs and symbols (airport décor) are part of passengers' expectations of the servicescape of an airport (Fodness \& Murray, 2007). Fewings (2001) mentions some airports that are particularly difficult to navigate and, as passenger numbers increase, the pressure to provide efficient signage to support passenger wayfinding first to check in and subsequently to the departure gate, via security, immigration, and shops. There are several principles at play in the design and placement of airport signage. Firstly, signage should be clear and unambiguous. Secondly, the signage should be at the point of need in time and space. Thirdly, the reader should immediately be able to see from the form of the sign if it is intended to communicate directions, identify a location, or reassure the reader that they are still going the right way (Fewings, 2001).

Gibbs (2014) found that passengers of all ages in New Zealand prefer to navigate terminals by being guided by static signs rather than asking airport staff or using digital tools. This means that static signs are given a good deal of attention by passengers. The choice of which languages and other elements to use on the signs, and how they are placed, is carefully thought out and not accidental.

\section{Analysis}

In early September 2016 the authors, along with some graduate students, arranged to visit Christchurch Airport. The group underwent induction and was signed in to allow admittance to airside facilities. The group was guided in a terminal walk through the domestic airside facilities, back to landside, then in to the airside international 
departure and arrival areas. We were able to take as many photos as we wished as we walked around. Our tour was arranged at a time when there were no international arrivals so we were able to move through those areas and take photos without disrupting passenger movements.

Subsequently the first author interviewed an airport services manager at the airport and in particular discussed a set of the images that the group had taken. The following analysis incorporates images and information from the visit and subsequent interview. It is particularly important to note that some of the images and signage we observed at that time have since changed. Within this context, we want to look in particular at two languages, Māori and Chinese. These languages were selected because they are both prominent at the airport but used for very different reasons. A number of signs and displays, including interactive screens, and TV/display screens, as well as badges worn by ground staff, were chosen for each language. This broader conception of signage is in line with Sebba's (2010) "mobile texts," which include texts such as banknotes, stamps, and bus tickets, which are rarely recognized as texts. These signs and displays were analyzed both inductively and deductively from the perspective of Aristotle's rhetorical triangle (logos - the text itself, pathos-the emotional appeal with its expected effect on the implied reader, and ethos-the character or intention of the implied speaker) as interpreted by Kinneavy (1980), with consideration of the relationship between the sender, receiver, and purpose of a sign, to reveal the intentionality and effect of the captured signs and displays. In addition, we consider the use of position order and size of text in different languages.

Burke's (1969) extension of this triangle to a pentad-agent (who?), action (what?),

scene (when and why?), purpose (why?), and agency (how?)-is also useful here. The interview data and other material are then brought to bear on the analysis of each of the signs, and emergent themes are identified and later discussed in the context of the educative function of the sign. We consider the origin of each sign or display and its purpose in a potential macro (national), meso (airport), or micro (individual) level in our analysis. Bell's (1984) "audience design" theory is also useful here. Audience design describes how speakers adapt their styles in response to who the audience is. Because signs are designed to be read, they are styled to deliver their messages to the intended audience (Juffermans, 2012).

In the following sections we examine a range of signage at Christchurch Airport that relate to wayfinding, behavior modification, language promotion, biosecurity, tourism, and the role of Māori in the linguistic landscape. In these sections we consider signs that have an element of Chinese language and those that we perceive as being intended for or particularly relevant to (among others) Chinese visitors, followed by signs that contain Māori language elements.

\section{Wayfinding}

The sign in Figure 5.1 is representative of a large number of navigational signs placed hanging from the ceiling throughout the airport (see website for Figure 5.1). It has 
a number of linguistic and other semiotic elements. There are three wayfinding destinations on the sign: "Baggage Reclaim," "Exit," and "Domestic Departure Gates 3-14." Arrows point in the direction visitors are to take. Pictograms illustrate "Baggage Reclaim" and "Departure," and these have Chinese, Japanese, and Korean translations in smaller text under the large English-language words. There is no translation or icon on this sign of the word Exit. The sign is black with white lettering and the only other color is the yellow background of the "Departure" icon. This kind of sign and its accompanying pictograms are subject to considerable design constrictions to be maximally readable, intelligible, and comprehensible to as many people as possible (Gupta, 2008).

Figure 5.1 Wayfinding sign inside terminal in English, Chinese, Japanese, and Korean, Christchurch International Airport, September 2016 (available online)

The sender of the sign is the airport on a meso level, and the decision of which languages to include on the sign would have been made at that level. Similarly, the relative size and order of the languages are not accidental and reflect what Scollon and Scollon (2003: 120) call "a system of preference." Chinese, Japanese, and Korean are the languages other than English spoken by most visitors arriving at the airport (Christchurch Airport, 2016). The decision not to accompany the important word Exit with translations and an icon is less easy to understand. The exact design of each sign may well be made by an individual employee, and the placement of the sign relevant to other signage may have made this information less important. In addition, international travelers may well recognize the English word Exit.

The sign has multiple implied receivers. Visiting and local passengers and other airport visitors who are literate in one or more of the languages of the sign are several such groups (Gupta, 2008). Still others will be able to understand the icons and arrows to find the Baggage Reclaim and the Departure area (Tan \& Said, 2015). As well as those who are able to read the sign, it is visible to those who cannot read all of the languages on the sign. If such a person notices the presence of other languages on the sign, this gives information about the presented linguistic policy of the place and about what languages (and by extension, their speakers) are ostensibly valued and welcomed there. Since many people in the airport are not literate in Asian languages, and the font used for these languages is relatively small, they may not even notice the presence of these languages on the sign (Pakarinen \& Björklund, 2018), but to those who see them, the message is clear. The purpose of the sign is therefore for navigational assistance for those who can read it or interpret the icon and as an indication of which languages are prioritized by the airport. It is in this respect notable that there is no presence of the Māori language on the sign or on any other informational sign. The interview with the airport services manager confirmed that Māori is not included in informational signs as all Māori speakers are also English speakers, unlike speakers of other languages involved in this chapter. The potential interpretation of this as deprioritizing the Māori language is contrasted by the use of Māori on other displays as described in the "Places to See" and "Māori Linguistic Landscape" sections below. 


\section{No Spitting}

The sign on the left of Figure 5.2 is in Chinese and Korean only. It has a large icon with a crossed-over picture of a person with drops of liquid apparently coming from the mouth. The message underneath the icon reads "No spitting anywhere" in Chinese and "No spitting" in Korean. The sender is, according to the information at the foot of the sign, the airport itself. The choice of languages is of interest here, as both Japanese and the main airport language, English, are absent from the sign. The implicit recipients are clearly literate in Chinese and Korean. Just as in the case of the navigational signs considered above, the choice of which languages to include is a way of directing the attention of those who can read the languages (Bell, 1984), but also perhaps a way of diverting the attention of those who are not being addressed. The lack of a message in English can make the sign inconspicuous to those who cannot read it. This could be a way of attempting to be discreet and avoid explicit racial profiling. In contrast, there was a report of a sign urging Chinese people not to spit, published just five days before the interview (Miller, 2016), which was mentioned by our interviewee: "I did see actually a newspaper report come out recently. I think it was the NZ Herald talking about a swimming pool where there was a sign that said 'Chinese people, do not spit', in English."

The presence of the "no spitting" sign immediately outside the terminal building was reminiscent of the reported publishing a few years ago of guidelines for Chinese tourists abroad (Guilford, 2013) and an associated fake news story (Hoaxbuster, 2013) about a nonexistent Chinese language sign outside the Louvre in Paris, forbidding those who could read it to defecate in public (Guilford, 2013). Unfortunately, this fake news was picked up and spread by other mainstream media (Le Figaro, August 22, 2013). Our surprise at seeing this "no spitting" sign at the airport may have been behind the fact that after the interview on subsequent visits to the airport we noticed that this sign had been removed from its place outside the terminal building.
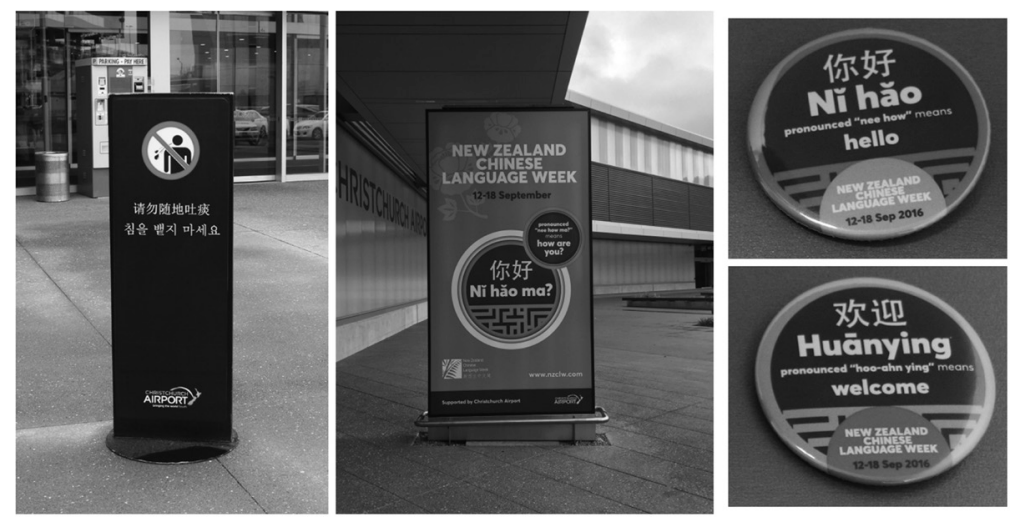

Figure 5.2 From left: "no spitting" sign in Chinese and Korean outside terminal; sign outside terminal for Chinese Language Week; staff buttons for Chinese Language Week, Christchurch International Airport, September 2016. 


\section{Chinese Language Week}

Chinese Language Week was celebrated the week after our visit, and this was observed at the airport in the presence of temporary signs outside the terminal building (center photo, Figure 5.2) and also by buttons worn by airport ground staff (right-hand photo, Figure 5.2). Not only is the fact that Chinese Language Week is upcoming mentioned on the signs, there is also a greeting in Mandarin, written in both simplified Chinese characters and in Pinyin. On another part of the sign, in a smaller font, the translation into English is given as well as instructions for the pronunciation of the greeting by English speakers.

The sender of the message, according to the sign, is New Zealand Chinese Language Week, which, according to the website linked on the sign (www.nzclw.com), is a registered Charitable Trust with the support of a number of key names in New Zealand, the Chinese Ambassador and the Race Relations Commissioner. The airport display was "supported by Christchurch Airport." Notably, the 2019 event is "endorsed by the Asia New Zealand Foundation, New Zealand China Friendship Society, New Zealand China Council, New Zealand National Commission for UNESCO, Immigration NZ, Tourism NZ, Education New Zealand, our major universities, Confucius Institutes and local body councils," and features a video endorsement from the prime minister, Jacinda Ardern. The intended message can perhaps be best understood in the words of our interviewee, the airport services manager:

[The sign] is a placement. We wanted to be proactive because the Chinese market is very important to the airport and the local economy, and is growing. We've recently attracted far more Chinese passengers-we have China Southern now, [and] China Airlines from Taiwan coming in. So, that just fits in with our general promotional market and engagement with the Chinese market. It's an opportunity to celebrate that connection, that partnership, and the welcoming of more Chinese visitors. And in conjunction with that we also have the staff wearing badges and even little buttons. It was great. We had all the staff learning key Mandarin phrases, even if it was just "hello".

When we asked who the signs were intended for, the answer was "the travelling public." Of course, this travelling public comprises both locally resident Chinese speakers and Chinese-speaking visitors who may be interested to see that English speakers are encouraged to learn a Chinese greeting, as well as nonChinese speakers who may be interested in learning Chinese greetings. The covert message then would be that the Chinese language and by extension its speakers are valued.

The week of our visit was actually Tongan Language Week (September 4-10, 2016), but we saw no information or recognition of that. There are no direct flights from Tonga to the airport, which may be an explanation. When asked about this lack of Tongan Language Week signage in the interview, our interviewee reported that there was not an explicit policy about which language weeks to observe, but that the Chinese market was important to the airport. We do not have data about whether for example Māori language week is celebrated at the airport, or which other holidays and the like are observed. 


\section{Biosecurity}

New Zealand is geographically fairly isolated from other parts of the world and this necessitates keeping out invasive species, parasites, and diseases that might affect people, animals, or plants, including farmed crops. The Ministry of Primary Industries monitors the borders, making sure that incoming international passengers have correctly filled in their biosecurity declaration cards. These are available in a number of languages. As passengers approach the biosecurity control area at the customs checkpoint they are exposed to an array of information. The message that is repeated in signage, regardless of the language used, is "Declare, dispose or pay the fine." This information is available in a multilingual sign placed above a baggage carousel and a Chinese-only sign indicating the "price" of attempting to bring in prohibited food items. Englishspeaking passengers are told that an illicit apple will cost them 400 NZD, while Japanese passengers are told that a jar of honey will cost them the equivalent amount in yen. Similarly, food items that Korean (root ginger, garlic, and ginseng) and Chinese speakers (medicinal plants) may wish to bring into New Zealand have price tags in the relevant currencies. In another display (left-hand photo, Figure 5.3) it is the Chinese speakers who are expected to be drawn to the photos of garlic, ginger, and ginseng. The center photo in Figure 5.3 is one of the strategically placed "amnesty bins" where forbidden items can be deposited without penalty. The text on this bin ("Please dispose here; declare, dispose or pay the fine of 400 NZD") is entirely in Chinese, while other bins in the area have text in English (right-hand photo, Figure 5.3). The sender
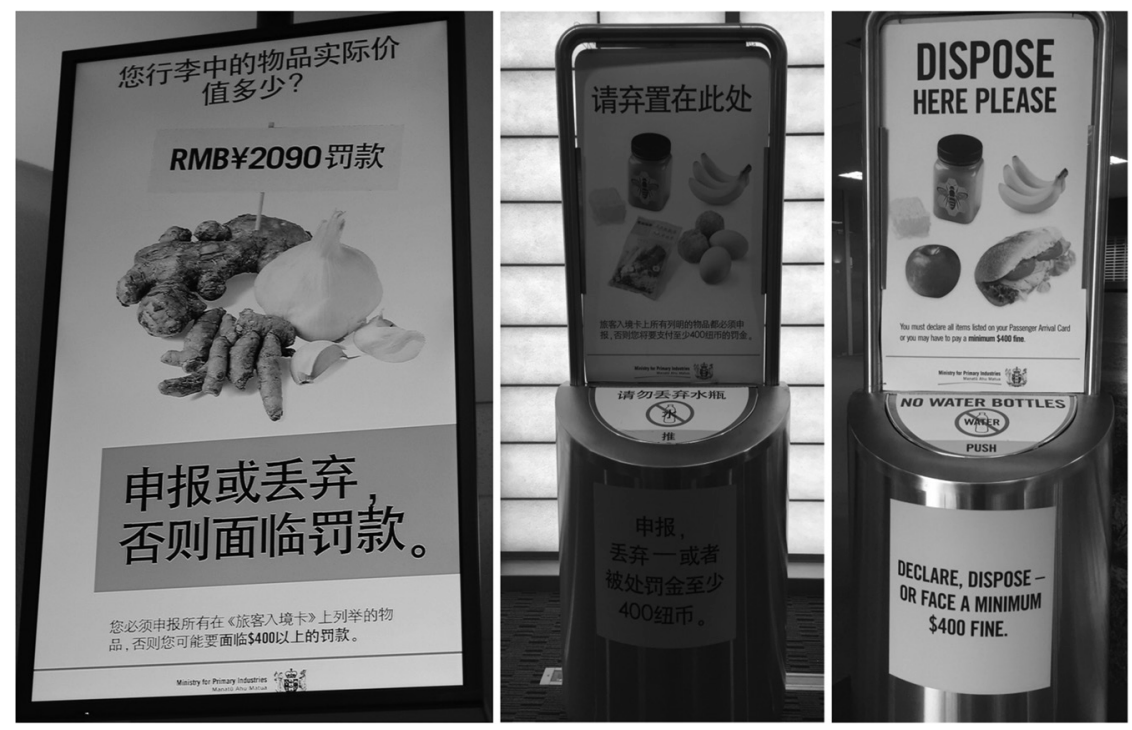

Figure 5.3 Chinese biosecurity sign before customs, Chinese biosecurity amnesty bin, English biosecurity amnesty bin, Chinese biosecurity sign before customs, Christchurch International Airport, September 2016. 
here is in all cases the Ministry for Primary Industries, while the intended recipients are all travelers, both local and visitors.

As mentioned above, the aim of this signage is to encourage compliance with New Zealand's biosecurity rules, through Voluntary, Assisted, Directed, and Enforced means. The point of this and other information is presumably to assist the traveler to comply voluntarily. The teaching that is going on is about which items are prohibited and that declaration will not be penalized. The recurring message "declare, dispose or pay the fine" is a matter of directing the traveler, apparently giving a choice, while the mention of the fine relates to the final level where enforcement is enacted.

The intended recipient is both the visitor, who may have previously been unaware of New Zealand's strict biosecurity rules, and the local resident, who is encouraged to inform future visitors about the need to avoid bringing prohibited items to New Zealand. There appears to be an assumption that speakers of Asian languages may bring food and medicinal items that they may believe are unavailable or expensive in New Zealand (Sherring, 2019), while English-speaking visitors are more likely to have a piece of fruit or a sandwich that they had taken with them from the plane. The principles of audience design (Bell, 1984; Juffermans, 2012) are clearly in operation here, with both the language and the content being tailored to the imagined reader.

\section{Places to See}

When incoming passengers approach passport control, they were (at the time of data collection) divided into holders of New Zealand, Australian, UK, US, and Canadian passports, who could be processed electronically through the SmartGate system, and others (including New Zealand permanent residents) who needed to stand in line to be processed by a passport officer. Those who are directed to the queues are offered the distraction of informational signs such as the sign in the top photo in Figure 5.4. These signs have information about tourism destinations in the South Island. The sender is given as the airport, but a logo indicating the airport's carbon-neutral certification competes for attention in the sign. Visitors are referred to south.co.nz for further information. South defines itself as a "focused group of all the South Island's 13 regional tourism organisations working collaboratively with Christchurch International Airport to grow international arrivals and length of stay in the South Island of New Zealand" (south.co.nz). The website appears to be aimed at both Chinese visitors (e.g. listing places where the Chinese app Alipay can be used), and also tourism operators, explaining how they may attract Chinese visitors in particular.

The recipient of the message of the sign is assumed to be a visitor to the South

Island, and they are given suggestions for places to see and taught some details in connection with the destination. One such example is the sign for Aoraki/Mount Cook shown in the top photo in Figure 5.4. Note that Aoraki/Mount Cook is the official name for this location in recognition of the original Māori name and a later English name given by European explorers. In this sign the visitor learns that Aoraki/ Mount Cook is New Zealand's highest mountain, that Sir Edmund Hillary (a) was a 


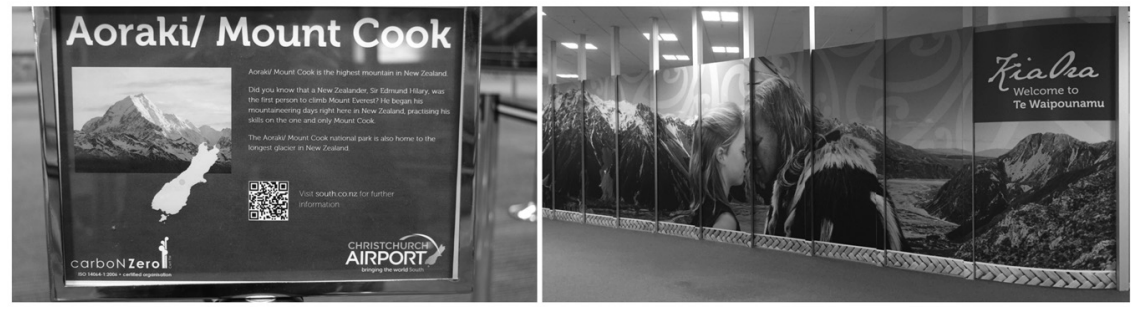

Figure 5.4 Tourist information before passport control (above); kia ora (informal greeting) sign between airbridge and duty free (below), Christchurch International Airport, September 2016.

New Zealander and (b) was the first person to climb Mount Everest and (c) climbed "Mount Cook" in his early days, and that the Aoraki/Mount Cook National Park has the longest glacier in New Zealand. Despite the use of the mountain's Māori name, Aoraki, there is no information about Māori history, cultural beliefs, or customs concerning the mountain. The sign also contains a QR code, which takes the visitor to the landing page of the south.co.nz website, which, at the time of writing, features a large photo of a smiling Asian couple.

The intention of the sign is, presumably, to show visitors possible destinations in the South Island. The south.co.nz website that it refers visitors to shows further destinations and itineraries with the stated intention "to grow the South Island economy and improve the experience that Chinese visitors enjoy when they come to New Zealand."

\section{Māori Linguistic Landscape}

Tereo Mãori (the Māori language) is the indigenous language of New Zealand and is one of its official languages. Since the 1980s Māori has been the focus of renowned revitalization efforts with particular focus on the education system and public broadcasting (Author 2, 2018). Due to its status and relatively high levels of government support, Māori sits at the top of a perceived hierarchy of minority languages in New Zealand (de Bres, 2015). As a result, Māori language and visual elements are increasingly used in signage and logos developed by government and local body authorities in order to "signify 'Māoriness"' and "commitment to Māori" (Sissons, 1993: 113). However, such expression of commitment does not mean that the use of Māori comes from a normalized perspective (Harlow, 2005). Instead, the use of Māori within Christchurch Airport is marked and can be perceived as tokenistic and exoticizing.

There are several examples of Māori words on display in the international arrivals section of the airport. The first is a large mural as passengers transition from the exit corridors after deplaning and move toward entering the duty-free area (bottom photo, Figure 5.4). Although there is no explicit information on the sign as to who the sender is, it is in fact the airport itself. 
The sign shown in the bottom photo in Figure 5.4 depicts a Māori elder welcoming a girl with a traditional hongi (noses pressed in welcome) in front of a photo of a high country scene. There is a band of woven flax along the bottom of the sign and a koru- styled Māori design in the sky of the image. Words of welcome are also included: Kia ora Welcome to Te Waipounamu (kia ora = welcome, greetings; Te Waipounamu = the South Island). The high-country scene matches other large textless murals of natural scenery, which could be seen in other parts of the airport at the time of the visit, including the baggage claim area. These vistas of the South Island landscape align with the airport's branding as the "gateway to the South Island."

We can consider a number of possible intentions in the use of Māori words and imagery on this sign. The words kia ora are in larger font, which would typically imply a higher level of importance. But, as noted by Kallen (2008: 277), font choices can also provide messaging. The cursive font used here is reminiscent of handwriting, with this particular choice invoking words written with an ink pen. Indeed, the writing of the " $\mathrm{r}$ " in the word ora uses a writing style that is no longer taught in schools in New Zealand and would be considered archaic. In other words, it is not clear that younger speakers of English would be able to decipher the word ora. So, while the font is large, the choice of font distances the viewer, conveying the contrasting messages of something that is both important (larger font) but also not meant to be fully understood (old-fashioned script). This message is further reinforced by the fact that none of the Māori words are translated, thus making it unclear how international visitors would read and interpret the message. If they can read English they will know that they are being welcomed somewhere, but not whether the welcome is to Christchurch, the South Island, or New Zealand? The intention of the sign, as shown by the South Island scenery, is to evoke the South Island but it is unclear whether this import is recognized by visitors.

Moving to the imagery in the photo montage, this also contains intended messages. The Māori man is wearing a traditional feathered cloak, so along with the woven flax border the message is one of exoticism. The interaction with the young girl involves a greeting ritual of pressing noses, which may be unfamiliar to many tourist visitors.

The sign can be perceived as providing some educational information to visitors in which it alerts visitors that there is another language in the landscape here and you may have some interaction with speakers of this language. However, most visitors to the South Island are unlikely to experience the encounter depicted. The formal attire of the Māori elder is something that would only be seen during a ritual welcome at a marae (traditional area in front of, and including, a meeting house). The marae setting is not depicted; instead the two people are placed in a montage in front of the high country scene.

Furthermore, this interaction is not an everyday one and not at all reflective of what a visitor might experience at one of the many tourism operations owned by the main Māori tribe in the South Island (Ngāi Tahu) or some of its subtribes. Ngāi Tahu is one of the largest tourism operators in New Zealand, owning a controlling interest in nine South Island businesses, which particularly focus on giving tourists experiences in the natural environment (Ngāi Tahu Tourism, 2018). For example, Ngāti Kurī, a subtribe, own the popular Whale Watch tours in the seaside township of Kaikōura, and 
Waewae Pounamu jade enterprise is owned by Ngāti Waewae in the West Coast town of Hokitika (see Carr, 2007 for an overview of Māori-operated tourism businesses).

In addition, the messages that are intended and received from this sign are often obscured by booths and bins of discount liquor and other items, which are placed in front of the mural to entice those moving into the duty-free area that visitors next progress through in order to reach immigration.

There is a second use of Māori language as the international arrivals transition from the customs check to landside as they exit to the meet-and-greet area. Here there are three large signs, two of which are shown in Figure 5.5, both featuring a scenic destination with a Māori word alongside an English phrase (see website for Figure 5.5).

Figure 5.5 From left: Taonga (treasure) and Haere mai (welcome) signs between customs and landside, Christchurch International Airport, September 2016 (available online).

In the sign on the left in Figure 5.5 the Māori word taonga (treasure) is prominently displayed on photos of South Island scenery. Again, the choice of font conveys an exoticism. The English words below highlight the word precious, thus linking back to the meaning of the Māori word. As with most other photos of scenery in the airport actual locations are given in English in small print at the bottom. The sign on the right in Figure 5.5 is the final sign as those arriving exit to landside. The photo depicts an iconic Christchurch scene of daffodils and blossom in reference to the fact that Christchurch is often described as the most English city in New Zealand. Again, the words of the Māori welcome phrase haere mai, are echoed by the Englishbelow.

The placement of these photos is on the side walls directly after the final luggage X-ray machine, about 20 meters behind the final exit door (which can be partially seen in the photo on the right-hand side of Figure 5.5). At this point in the arrival process, international visitors, many of whom have arrived on long haul flights, will be focused on exiting from airside to landside and many transiting through this area will not notice these images. The educational intent of these signs is similar to the one as visitors deplane (Figure 5.4).

Both sets of signs are located at threshold points: as those arriving leave the plane and as they exit to landside. The Māori language is often used symbolically at the beginning and end of government and local body meetings (McKee \& Manning, 2015) and here the placement of the signs is reminiscent of this symbolic use at the entrance and exit.

All of these signs include scenic images to cohere with the airport's branding. In fact, this seems to be the main intention of the signs. The use of Māori words appears to be symbolic; cohering to expected norms about the use of Māori in the New Zealand setting, the Māori words are not directly translated. The use of cursive, decorative fonts, and flourishes for Māori words suggests that they may not be expected to be read or even to be legible to the visitors. This may be an example of what Canagarajah (2012: 7) calls languages being "appropriated by people for their purposes."

In the interview with the airport services manager, it was revealed that the Māori words were selected and used by the marketing team without consultation or advice 
from the local tribe. Internationally the use of Indigenous languages and cultural motifs are regularly used without approval to add an exotic flavor to the tourism experience (Gertner, 2019). This can be contrasted with the way Auckland Airport refers to how it has collaborated with local Māori in developing their thirty-year plan (Auckland Airport, 2019). Auckland Airport cites that it values "the cultural advice and services local Māori provide, including pōwhiri (Māori welcome ceremonies) for the new airlines we welcome to Auckland each year." Auckland Airport also supports Māori Language Week by making announcements in Māori and hosting performances by Māori cultural groups in its terminals. This is an example of the increasing engagement with appropriate Māori groups to add depth to the usage of Mãori iconography and language in recognition that "the power of the tribal narrative significantly enhances the tourism experience" (Roskruge, Morrison, \& Maxwell. 2017).

\section{Discussion}

We have shown that signs in airports can have a range of educative functions. From the airport's point of view, there are two central purposes: to assist the efficient movement of passengers and to market attractions at the destination. Much linguistic landscape research is done in public spaces. An airport, however, is not a street, but rather a relatively controlled area. Since it is a semipublic than a public space, all the signs we saw were officially generated and sanctioned by the airport and/or government agencies. As an educational arena, there are many differences to classroom-based education. In the airport, signs are more contextualized and their presence is presumably carefully thought out. The rhetorical triangle or pentad is curated to provide appropriate information to the right recipients at the right time. However, some of the implicit educational messaging, such as the strategic employment of Māori words and images, may be lost due to competition for the attention of visitors from commercial advertising in the duty-free area (Figure 5.4) and the proximity of the exit (Figure 5.5).

The signs we have focused on in this chapter have been mostly permanent and stationary, although some were temporary, such as the Chinese Language Week signs outside the airport, and also mobile (Sebba, 2010) in the case of the Chinese buttons worn by ground staff. Visitors arriving at the airport (the primary group of implicit readers of the signs in the airport) have a range of assumed educational needs. Firstly, they are given extensive guidance in key languages and pictograms to help them to successfully navigate the airport. Then they are taught how to avoid falling foul of the strict New Zealand biosecurity rules. Furthermore, they gain knowledge about what to do in the South Island through explicit tourist information and images of empty natural scenery. Signs placed where queues form offer fun facts about New Zealand and New Zealanders who may be known to visitors. Other pictures show the visitors what they might expect to see in New Zealand with images of beautiful nature and a formal encounter with Māori, but there is an absence of images of mainstream New Zealand society. 
Education beyond the classroom is not only relevant for young people. Signage with an educational intention is found in many environments and this has not been the focus of much research before the current volume. The educative content of airport signage has not to our knowledge been investigated previously. Signs, like written texts in many genres, offer not only the written word, but also the social semiotic context and content of the sign. Shohamy and Waksman (2009) point out that semiotic processes can only be understood by multimodal approaches and insist on attention "not only to the meanings conveyed by the language, but also to the meaning provided by the visual aspects of language like typography, placement in the semiotic layouts, color, spatial and kinetic arrangements" (Shohamy \& Waksman, 2009: 316). The analysis of airport signs bears witness to this. In Figure 5.4, the stylized retro font used in the words kia ora amplifies the image of a Māori elder greeting a European-looking young woman in its role as a decorative evocative element superimposed in a scene of natural beauty, which is otherwise devoid of any trace of human occupation. The same theme can be seen in Figure 5.5 where a huge, ornate font marks a Māori word or phrase as decorative rather than denotative.

Similarly the use of a QR code in Figure 5.4 to link the reader to further information

from other sources is a selective appeal to those who command the requisite literacies (digital savvy visitors who have a mobile device at hand with the capability of scanning a QR code along with connectivity to allow the visitor to access the linked webpage). This is covertly selective just as the use of only two languages in the left-hand image in Figure 5.2 is a way of attracting the attention of those who are being addressed while remaining invisibilized in the background for others.

We would like to extend Spolsky's (2009) enumeration of types of signs to highlight the educational function of "informative" signs. We have shown that information that is intended to facilitate learning of an imagined reader or group of readers can be considered to have an educative purpose, regardless of whether the intended learning outcomes are knowledge of how to get around independently (Figure 5.1), of the informal rules such as cultural differences and acceptable behavior or of the formal rules of the country (Figure 5.2), or of tourist attractions that could be included in a tour (Figure 5.4). The intended learning outcome of the signs referring to Chinese Language Week in Figure 5.2 is that Chinese is a valued language and Chinese speakers are especially welcome (and may even be greeted in Chinese), while Figures 5.4-5.5 convey multiple messages through their layered semiotic construction, but visitors may pick up on that there is a Māori language and a culture present in New Zealand, though there is a lack of links to further information. Together with the elaborate graphic design it is tempting to conclude that the presence of Māori in the airport is as a decorative, exotic element, with no real content.

In conclusion, this study reveals a range of educative functions and intended messages (as well as some unintended ones) conveyed by signage in the semipublic space of airports. Because the airport in this study is owned by a local government/ government body these educative functions extend to reinforcing government priorities through the use of languages, which have identity functions and economic import. 


\section{References}

King, J. (2018). Māori: Revitalization of an endangered language. In K.L. Rehg \& L. Campbell (Eds.), The Oxford handbook of endangered languages (pp. 592-612). Oxford: Oxford University Press.

Aiestaran, J., Cenoz, J., \& Gorter, D. (2010). Multilingual cityscapes: Perceptions and preferences of the inhabitants of Donostia-San Sebastián. In E. Shohamy, E. Ben- Rafael, \& M. Barni (Eds.), Linguistic Landscape in the City (pp. 21934). Bristol: Multilingual Matters.

Auckland Airport. (2008). Our Brand New Welcome Experience. Auckland: Auckland Airport. Retrieved from https://www.aucklandairport.co.nz/ /media/426D09A08C684 F12B16866D049227C92.ashx?sc_database=web

Auckland Airport. (2019). Engaging with local Māori. https://corporate.aucklandairport. co.nz/corporate-responsibility/engagingwith-local-maori.

Bell, A. (1984). Language style as audience design. Language in Society, 13(2), 145-

204. Blow, C. J. (2013). Airport Terminals: Butterworth Architecture Library of

Planning and Design. Oxford: Butterworth-Heinemann.

Bradley, G. (2017). Tourism roars past dairy as NZ's biggest export earner. New Zealand Herald, $30 \quad$ April. $\quad$ Retrieved from https://www.nzherald.co.nz/business/news/article. cfm?c_id=3\&objectid=11847120

Burke, K. (1969). A Rhetoric of Motives. Berkeley: University of California

Press. Carr, A. (2007). Māori nature tourism businesses: Connecting with the

land. In R.

Butler \& T. Hince (Eds.), Tourism and Indigenous Peoples (pp. 113-27). Amsterdam: Butterworth-Heinemann.

Canagarajah, S. (2012). Translingual Practice: Global Englishes and Cosmopolitan

Relations.

New York: Routledge.

Castro, R., \& Lohmann, G. (2014). Airport branding: Content analysis of vision statements. Research in Transportation Business and Management, 10, 4-14.

Cenoz, J., \& Gorter, D. (2006). Linguistic landscape and minority languages. International Journal of Multilingualism, 3, 67-80.

Christchurch Airport (2016). Our Place in the World: Annual Report. Christchurch: Christchurch Airport. Retrieved from https://www.christchurchairport.co.nz/ media/830702/cial_annual_report_main_report_spreads.pdf

Coupland, N., \& Garrett, P. (2010). Linguistic landscapes, discursive frames and metacultural performance: The case of Welsh Patagonia. International Journal of the Sociology of Language, 2010(205), 7-36.

de Bres, J. (2015). The hierarchy of minority languages in New Zealand. Journal of Multilingual and Multicultural Development, 36(7), 677-93.

Fewings, R. (2001). Wayfinding and airport terminal design. Journal of Navigation, 54(2), 177-84. doi: 10.1017/S0373463301001369

Fodness, D., \& Murray, B. (2007). Passengers' expectations of airport service quality. Journal of Services Marketing, 21(7), 492-506.

Gertner, R. K. (2019). The impact of cultural appropriation on destination image, tourism, and hospitality. Thunderbird International Business Review, 61(6), 87377.

Gibbs, J. (2014). Passenger perceptions of depersonalisation of the airport experience. master's thesis, University of Otago.

Gorter, D. 2018. Linguistic landscapes and trends in the study of schoolscapes. Linguistics and Education, 44, 80-5. 
Guilford, G. (2013). Chinese government publishes guide on how to avoid being a terrible tourist. The Atlantic (7 October). https://www.theatlantic.com/china/ archive/2013/10/chinese-government-publishes-guide-on-how-to-avoidbeing-a- terrible-tourist/280332/

Gupta, I. (2008). Public signage system to combat problems of illiteracy and multilingualism. Journal of International Social Research, 1(4), 268-78.

Harlow, R. (2005). Covert attitudes to Māori. International Journal of the Sociology of Language, 172, 133-47.

Hayward, J. (2012). Biculturalism-Biculturalism in the state sector, Te Arathe Encyclopedia of New Zealand, http://www.TeAra.govt.nz/en/biculturalism/page-2

Hoaxbuster. (May 1, 2013). Panneau anti-chinois au Louvre. https://www.hoaxbuster.com/ societe/2013/10/04/panneau-anti-chinois-aulouvre

Jameson, J. (2019). Jewel Changi Airport, Singapore: First look at gamechanging new development', Stuff, 12 April. Retrieved from https://www.stuff.co.nz/travel/ destinations/asia/111985651/jewelchangi-airport-singapore-first-look-at- gamechanging-new-developmentjewel (accessed August 25, 2019).

Juffermans, K. (2012). Multimodality and audiences: Local languages in the Gambian linguistic landscape. Sociolinguistic Studies, 6(2), 259-84.

Kallen, J. (2008). Tourism and representation in the Irish linguistic landscape. In E. Shohamy \& D. Gorter (Eds.), Linguistic Landscape: Expanding the Scenery (pp. 270-83). New York: Routledge.

Kinneavy, J. L. (1980). A Theory of Discourse: The Aims of Discourse. New York: W.W. Norton \& Company.

Landry, R., \& Bourhis, R. Y. (1997). Linguistic landscape and ethnolinguistic vitality: An empirical study. Journal of Language and Social Psychology, 16, 23-49.

Le Figaro. (August 22, 2013). La Chine s'inquiète de l'incivilité de ses touristes. http:// www.lefigaro.fr/international/2013/08/22/0100320130822ARTFIG00340-la-chine-s- inquiete-de-l-incivilite-de-ses-touristes.php

Macalister, J. (2006). The Maori presence in the New Zealand English lexicon, 18502000: Evidence from a corpus-based study. English World-Wide, 27(1), 1-24. doi: 10.1075 / eww.27.1.02mac

McKee, R. L., \& Manning, V. (2015). Evaluating effects of language recognition on language rights and the vitality of New Zealand Sign Language. Sign Language Studies, 15(4), 473-97.

Miller, C. (2016). How racist are we New Zealand? New Zealand Herald (5 January). https://www.nzherald.co.nz/nz/news/article.cfm?c_id=1\&objectid=11776 745

New Zealand Government. (2019). Māori culture and heritage. https://www.govt.nz/ browse/history-culture-and-heritage/maori-languageculture-and-heritage/maori- culture-and-heritage/

Ngāi Tahu Tourism (2018). https://www.ngaitahutourism.co.nz/

Pakarinen, S., \& Björklund, S. (2018). Multiple language signage in linguistic landscapes and students' language practices: A case study from a language immersion setting. Linguistics and Education, 44, 4-11.

Paranihi, R. (2019), New Māori look for Auckland Int. Airport, Te Ao Mãori News, 23 May. Retrieved from https://teaomaori.news/new-maori-look-auckland-intairport

Roskruge, M., Morrison, S., \& Maxwell, T. K. (2017). Measuring the value of the contribution of Māori language and culture to the New Zealand Economy. Retrieved from https://www.tetaurawhiri.govt.nz/assets/Uploads/46b6fdcf03/Measure-thevalue- of-te-reo-Maori2.pdf 
Royal Society of New Zealand. (2013). Languages in Aotearoa New Zealand. Retrieved from https://www.royalsociety.org.nz/assets/Uploads/Languagesin-Aotearoa-New- Zealand.pdf

Scollon, R., \& Wong Scollon, S. (2003). Discourses in Place: Language in the Material World. London: Routledge.

Sebba, M. (2010). Discourses in transit. In C. Thurlow, \& A. Jaworski (Eds.), Semiotic Landscapes: Language, Image, Space (pp. 59-76). London: Continuum.

Sherring, P. (2019). Declare or dispose: Protecting New Zealand's border with behaviour change. Journal of Social Marketing. doi: 10.1108/JSOCM-09-20180103

Shohamy, E., \& Waksman, S. (2009). Linguistic landscapes as an ecological arena: Modalities, meanings, negotiations, education. In E. Shohamy \& D. Gorter (Eds.), Linguistic Landscape: Expanding the Scenery (pp. 313-31). New York: Routledge.

Sissons, J. (1993). The systematisation of tradition: Maori culture as a strategic resource, Oceania, 64(2), 97-116.

Spolsky, B. (2009). Prolegomena to a sociolinguistic theory of public signage. In E. Shohamy \& D. Gorter (Eds.), Linguistic Landscape: Expanding the Scenery (pp. 2539). New York: Routledge.

Spolsky, B., \& Cooper, R. L. (1991). The Languages of Jerusalem. Oxford: Clarendon Press. Stats N. Z. (2018). International visitor arrivals to New Zealand: December 2017.

Retrieved from www.stats.govt.nz/information-releases/international-visitorarrivals- to-new-zealand-december-2017

Tan, M. S., \& Said, S. B. (2015). Linguistic landscape and exclusion: An examination of language representation in disaster signage in Japan. In R. Rubdy \& S. B. Said (Eds.), Conflict, Exclusion and Dissent in the Linguistic Landscape (pp. 145-69). London: Palgrave Macmillan.

Tsui, K., \& Henderson, I. (2018). The changing dynamics and roles of New Zealand's airports: An overview. Airline Economics in Asia (Advances in Airline Economics), 7, 245-66. 